\title{
Effect of postpartum anaemia on maternal health-related quality of life: a systematic review and meta-analysis
}

Ernest Moya ${ }^{1,2^{*}}$, Nomsa Phiri ${ }^{1}$, Augustine T. Choko ${ }^{3}$, Martin N. Mwangi ${ }^{1,2}$ and Kamija S. Phiri ${ }^{1,2}$

\begin{abstract}
Background: Postpartum anaemia remains a persistent and severe public health issue in many parts of the world. Studies have reported mixed findings on the effects of anaemia during the postpartum period on maternal healthrelated quality of life (HRQoL). We conducted this systematic review to summarise available evidence to inform public health practitioners on whether 1) anaemia negatively impact maternal health-related quality of life and 2) whether iron supplementation in anaemic women can improve maternal HRQoL during the postpartum period.

Methods: This review's protocol was registered online with PROSPERO (CRD42020206618). We extensively searched Embase, PubMed, Cochrane and Scopus through the HINARI website to identify studies that reported either association or effect of postpartum anaemia on fatigue, depression and mother-child interaction. We restricted our search to studies of human females published in English language from databases inception until August 2020. We followed a Cochrane guideline for reporting systematic reviews and meta-analysis to synthesise data.

Results: Twenty-seven studies were included in this systematic review, with some reporting all three domains (fatigue, depression and mother-child interaction) of HRQoL. Seven observational studies with pooled dichotomous outcomes showed that iron deficient or anaemic women were 1.66 times more likely to experience symptoms of depression than non-anaemic or iron-replete women $\left[R R=1.66(95 \% \mathrm{Cl}: 1.28 ; 2.16), \mathrm{I}^{2}=67.0 \%, P<0.01\right]$. In three randomized controlled trials (RCTs), pooled continuous data showed statistically significant reduction in fatigue scores in women who received iron supplementation than the control group [MD: $-1.85(95 \% \mathrm{Cl}:-3.04 ;-0.67), \mathrm{I}^{2}=65.0 \%$, $p<0.06]$. Two of the four included studies showed that anaemic mothers were less responsive and had negative feelings towards their children than non-anaemic mothers.
\end{abstract}

Conclusion: Evidence from this review suggests that postpartum anaemia negatively affects health-related quality of life and that iron replenishment improves both symptoms of fatigue and depression. Nevertheless, it remains unclear whether postpartum anaemia affects mother-child interaction.

Keywords: Anaemia, Iron deficiency anaemia, Depression, Fatigue, Mother-child interaction, Systematic review

*Correspondence: emoya@cartafrica.org

${ }^{1}$ Training and Research Unit of Excellence (TRUE), 1 Kufa Road, Chichiri, BT3, PO Box 30538, Blantyre, Malawi

Full list of author information is available at the end of the article

\begin{abstract}
Background
Postpartum anaemia remains a persistent and severe public health issue in many parts of the world [1]. The World Health Organisation defines postpartum anaemia as a haemoglobin concentration of $<11 \mathrm{~g} / \mathrm{dl}$ at one week post-delivery and $<12 \mathrm{~g} / \mathrm{dl}$ in the first postpartum year [2]. Although maternal iron stores are expected
\end{abstract}


to replenish after delivery, the prevalence of anaemia in women after childbirth remains unacceptably high in both developed (22-50\%) and developing (50-80\%) countries [3]. Postpartum anaemia is mainly caused by untreated antenatal iron deficiency or anaemia and excessive blood loss during or after childbirth [3]. Postpartum anaemia is classified as anaemia due to iron deficiency in many women $[1,4]$. Iron deficiency anaemia (IDA) is the state in which there is insufficient body iron to maintain the tissue's normal physiological function, i.e. blood, brain and muscles [5]. A reduction of serum ferritin below $30 \mu \mathrm{g} / \mathrm{l}$ in settings where inflammatory conditions are uncommon is suggestive of iron deficiency (ID) [5].

Untreated postpartum anaemia affects the wellbeing of both the mother and child. Maternal ID or anaemia related complications may impair physical capacity and performance and negatively impact health-related quality of life [6]. Health-Related Quality of Life (HRQoL) is the patient's self-report on how her wellbeing and functioning level are affected by individual health or medical treatment received [7]. There is now consensus that HRQoL is a multidimensional construct. At a minimum, it consists of the physical, mental and social domains. Symptoms such as fatigue, psychological distress (anxiety and depression) and altered motherchild relationship, among others, are common indicators of poor HRQoL.

Since health care is becoming more patient-centred, patient-reported outcomes such as quality of life are increasingly important [8]. Worldwide, studies have reported mixed results on the association between postpartum anaemia and maternal HRQoL. For example, Chandrasekaran et al. (2018) [9] reported no association between postpartum anaemia and HRQoL. Conversely, Khalafallah et al. (2012) [10] found a strong association between maternal iron stores and improved HRQoL. Due to controversies surrounding the role of iron deficiency or anaemia on maternal HRQoL and the fact that improved maternal HRQoL after childbirth is linked to the improved wellbeing of the child and "family and society"[11]; reaching a consensus can be influential in deciding whether postpartum iron supplementation improves maternal wellbeing. Therefore, we conducted a systematic review to determine the effect of postpartum anaemia on maternal HRQoL in the first postpartum year. In assessing the effect of iron deficiency or anaemia on HRQoL, we used the Wilson and Cleary model [12], which links the biological and physiological variables (iron and haemoglobin levels) to measures of HRQoL such as symptom status (fatigue, depression) and functional status (mother-child interaction).

\section{Method}

\section{Protocol registration}

This review's protocol was registered online with PROSPERO (CRD42020206618) following the Preferred Reporting Items for Systematic Reviews and Meta-analysis [13].

\section{Search Strategy}

We searched PubMed, Embase, Cochrane and Scopus through the HINARI website. For PubMed, we used English MeSH keywords: "anaemia", "iron deficiency", "health-related quality of life", "depression", "bonding" and "postpartum women" with attention to possible synonyms, spelling variants, and correct use of truncation and Boolean operators (Additional file 1). Using search terms for PubMed, we developed a search strategy for Embase by entering one term at a time, and a correct term was selected on Emtree (Additional file 1). We restricted our search to studies of human females published in English from databases inception until August 2020. After that, the results were directly exported into EndNote reference management software (Endnote 2017), and all duplicates were removed. We also manually searched references of included articles for additional relevant studies.

\section{Study Selection (inclusion and exclusion)}

Studies were included according to PICO: 1) Population: epidemiological studies (randomised and nonrandomised-controlled trials, cohort, case-control and longitudinal cross-sectional studies) that reported either the effect or association between anaemia or iron deficiency during the postpartum period [14] and measure of HRQoL either fatigue or depression or mother-child interaction; 2) Intervention/Exposure: any form of postpartum iron supplementation or haematological test confirming anaemia/iron deficiency and questionnaire confirming PPD or fatigue or mother-child interaction; 3) Comparison: placebo or standard treatment or those that showed HRQoL indicators in anaemic and nonanaemic women and 4) Outcome; effect of (experimental studies) or association (observational studies) of anaemia or iron deficiency on fatigue, depression and motherchild interaction. Other study designs such as cross-sectional, case series, narrative reviews and commentaries were excluded. Additionally, qualitative study designs were excluded from this review.

\section{Data extraction and management}

A standardised, piloted data extraction form was used to extract data from included studies. Two independent reviewers (EM and NP), working in parallel, screened titles and abstracts of the identified articles. After that, full articles were retrieved for further evaluation. 
Discrepancies between the two reviewers were resolved through discussion. Disagreements between the two were resolved through discussion with MNM and KP. For studies with dichotomous outcomes, we extracted the number of events and participants in each group. We extracted the effect measure, which included both crude and adjusted ratios with their respective $95 \%$ confidence intervals and p-values. We extracted means and standard deviation for continuous outcome with normally distributed data while medians, range and p-value of the nonparametric test were extracted for continuous skewed data. We also extracted correlation coefficients for correlation studies and median or mean change from baseline for longitudinal studies.

\section{Risk of bias assessment}

Two reviewers (EM and NP) independently assessed the risk of bias in the included studies, and discussions resolved disagreements. For randomised trials, we used a revised Cochrane risk-of-bias tool for randomised trials (RoB-2). Thereafter the risk of bias in the individual study was judged as either "low risk" or "moderate risk" or "high-risk bias" [14]. The Newcastle-Ottawa Scale was used to assess the risk of bias for cohort studies and case-control studies [15]. We considered studies rated with $\geq 7$ stars as good (moderate risk) [16]. We adopted and modified a tool for evaluating the risk of bias in nonrandomised studies of interventions (ROBINS-I) for longitudinal observational studies [17]. We assessed bias due to confounding, selection of participants, missing data, measurement of outcome, and selecting the reported outcomes. We dropped two domains that assess bias due to intervention classification and deviations from the intended interventions as these were deemed not applicable [17].

\section{Grading of evidence}

We graded the quality of evidence using the Grading of Recommendations Assessment, Development and Evaluation (GRADE) [18]. The assessment criteria included; risk of bias, indirectness, imprecision, inconsistency and publication bias. Thereafter, the strength of evidence was grouped as "high", "moderate", "low", or "very low".

\section{Data synthesis}

Data analysis was performed using Stata SE for Windows V.14.1 (StataCorp, College Station, Texas, USA). Data has been grouped and analysed separately depending on study design (observation and experimental) and whether the study has reported the effect of maternal anaemia on either fatigue, depression or mother-child interaction. We presented risk ratios (RR) for study level comparison of binary outcomes and mean difference (MD) for the pooled continuous data. We used Mantel-Haenszel random-effects model to calculate pooled RR and 95\% confidence interval (CI). A random-effects model was used to calculate pooled MDs. We used recommended formulas to calculate the estimated sample mean and SD from the sample size, median, range and/or interquartile ranges [19]. Wherever fatigue was reported with multiple scales, such as on the multi-dimension fatigue inventory (MFI) scale, the overall "general fatigue" was selected. The $\mathrm{I}^{2}$ statistic was used to quantify statistical heterogeneity. We used Cochrane recommendation to interpret $\mathrm{I}^{2}$ statistics as "might not be important" (0-40\%), "moderate" (30 $60 \%)$, "substantial" (50-90\%) or "considerable" (75\%$100 \%)$. We planned to assess publication bias using funnel plots, but this was not possible because, in each meta-analysis, there were less than ten studies. Thus, we used visual inspection of the confidence intervals. The findings were considered to be statistically significant if the reported P-value was $<0.05$.

\section{Results \\ Study characteristics and methodological quality}

The searches in Embase, PubMed, Cochrane Central Trial, and Scopus databases through the Hinari website identified 7,547 citations, of which 82 (1.1\%) full articles were extracted and assessed for their eligibility. Of the 82 articles, 27 (32.9\%) met the eligibility criteria. We further included one article identified by searching the references of the included articles (Fig. 1). Tables 1, 2 and 3 summarise the characteristics and methodological quality of the eligible studies.

\section{Postpartum anaemia and maternal depression}

Out of 18 studies that reported the effect or association between postpartum anaemia and depression, 15 studies were planned to be included in a meta-analysis. Meyer et al. (1995) [43] was not included as the study reported symptoms of postpartum blues and not depression. Holm et al. (2019) [24] and Güven et al. (2020) [44] were excluded due to a lack of sufficient information. Authors for both studies were contacted but did not provide the missing information by the time submission was made. However, all the three excluded studies reported a significant decrease in depression scores with a corresponding increase in haematological parameters (Table 1).

Ten of the remaining 15 studies were observational studies [9, 21, 25-32] and 5 were RCTs. [20, 22, 23, 33, 34] The comparison of depression scores in eight observational studies was dichotomous. One study [32] was not included in a meta-analysis as it was not consistent with zero events in the non-exposed group. The pooled 


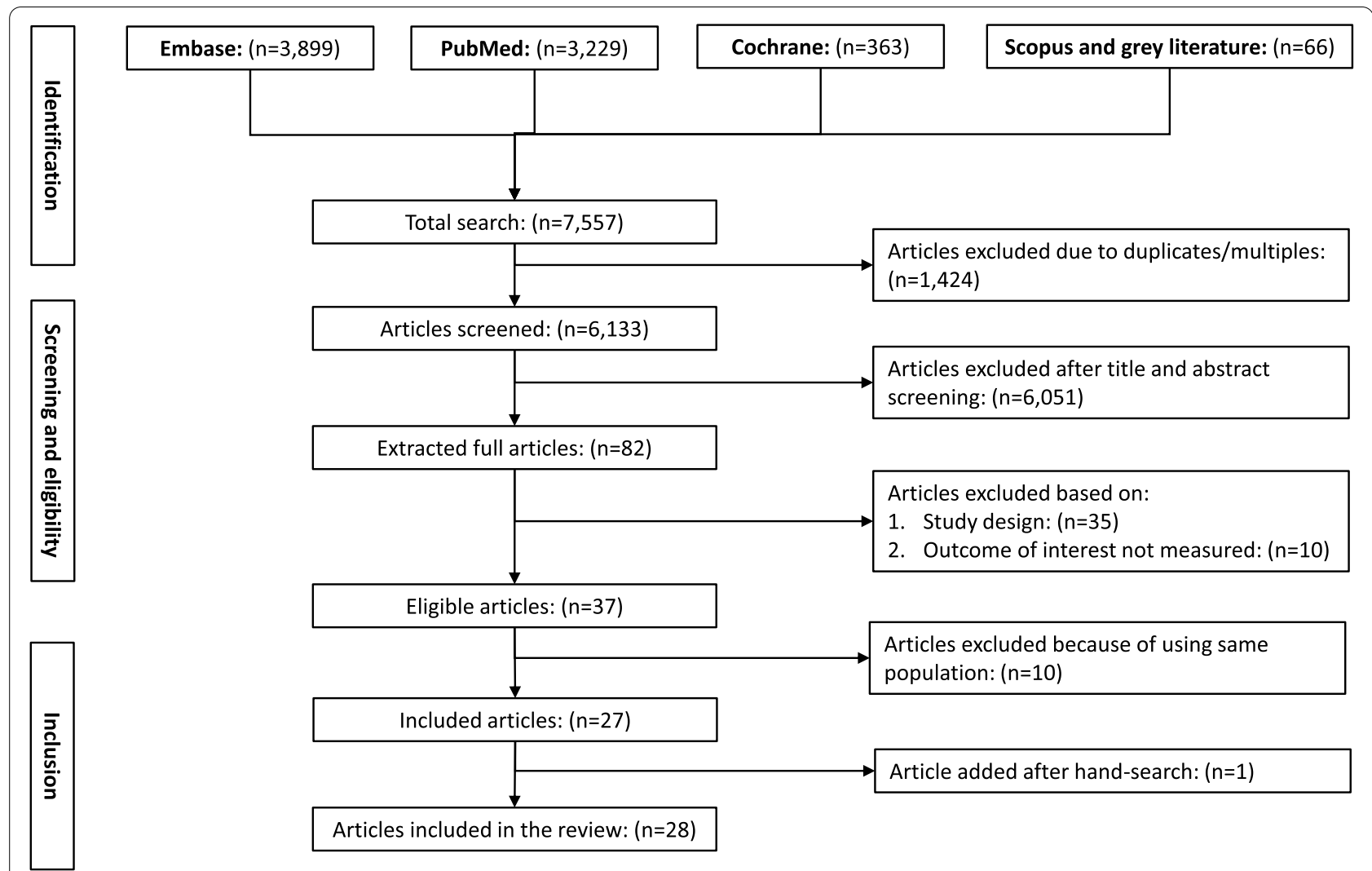

Fig. 1 Process of selecting studies for inclusion in the systematic review

results of the remained seven studies [21, 25-32] showed that iron deficiency or anaemic women were 1.66 times more likely to experience symptoms of depression than the non-anaemic or iron-replete women and the findings were statistically significant [(heterogeneity estimate: $\mathrm{I}^{2}=67.0 \%, p<0.01$ ), and $\mathrm{RR}=1.66$ (95\% CI: 1.28 ; 2.15)] (Fig. 2). Two observational studies [29, 31] measured depression as a continuous outcome, and their findings were not pooled together but reported separately (Table 1).

Similar findings were observed in four of five RCTs $[20,22,23,25]$ that measured depression as a continuous outcome. The pooled results in these four studies $[n=739$ (treatment group $=372$ and control group $=367)$ ] showed a significant reduction in depression scores for women who were given intravenous iron than oral iron or placebo group based on random mixed model $(\mathrm{MD}=-1.48,95 \% \mathrm{CI}:-2.53 ;-0.42)$. However, heterogeneity was considerable high $\left(\mathrm{I}^{2}=61.0 \%, p=0.05\right)$ (Fig. 3). Perello et al. (2014) [21] was not included in the meta-analysis as the outcome measure depression was reported differently with others ( categorical outcome) and findings in this study are present in Table 1.

\section{Postpartum anaemia and fatigue}

Eleven studies reported either the effect or association between postpartum anaemia and fatigue (Table 2). Four studies [27, 32, 38, 39] were excluded from a meta-analysis due to insufficient information. Westad et al. (2008) [36] reported marked improvement in physical fatigue scores corresponding with rapid iron stores replenishment in women in the intervention group than the control group at 4,8 and 12 weeks postpartum $(p=0.02$, $p=0.02$ and $p=0.03$ respectively). However, it was excluded from analysis as the author did not provide missing information until submission.

Pooled continuous data from three RCTs [20, 22, 24] (Fig. 4) showed statistically significant reduction of fatigue scores in women who received iron supplementation or vitamins that led to haematological increase than the control (MD: $-1.85,95 \% \mathrm{CI}:-3.04 ;-0.67)$ but with considerable heterogeneity $\left(\mathrm{I}^{2}=65.0 \%, p<0.06\right)$. Fatigue scores were reported as a categorical outcome in two studies. Hatzis et al. (2003), [37] in their matched intervention study in Greece, reported that women who received recombinant human erythropoietin reported fewer clinical symptoms of fatigue $(p=0.0012)$ compared 
Table 1 Study characteristics and association between anaemia or iron deficiency during postnatal period and maternal postpartum depression

\begin{tabular}{|c|c|c|c|c|}
\hline Author \& Year & $\begin{array}{l}\text { Study Design and } \\
\text { Setting }\end{array}$ & Risk of Bias & Assessment Tool & $\begin{array}{l}\text { Effect measure and } \\
\text { Significance }\end{array}$ \\
\hline Sheikh et al. 2015 [20] & $\begin{array}{l}\text { RCT double-blind, pla- } \\
\text { cebo; Iran }\end{array}$ & Low & $\begin{array}{l}N=70 \text { (iron supplementa- EPDS (cut off: } \geq 11 \text { ) } \\
\text { tion; } 35 \text {, placebo; } 35 \text { ) }\end{array}$ & $p=0.03$ \\
\hline Perello et al. 2014 [21] & RCT double-blind; Spain & Low & $\begin{array}{l}\quad N=72 \text { anaemic (ferrous EPDS (cut off: } \geq 11 \text { ) } \\
\text { sucrose + oral iron; } 36 \\
\text { placebo + oral iron; } 36)\end{array}$ & $P>0.05$ \\
\hline Beard et al. 2005 [22] & $\begin{array}{l}\text { RCT, double-blind; South } \\
\text { Africa }\end{array}$ & Low & $\begin{array}{l}N=95 \text { (30 in IDA-PL, } 34 \text { in EPDS (cut off: } \geq 10 \text { ) } \\
\text { IDA-Ferrous, \& } 31 \text { in control) }\end{array}$ & $P<0.005$ \\
\hline Hamm et al. 2020 [23] & RCT open label; USA & Moderate & $\begin{array}{l}\quad N=66 \text { (single RBCs; 33, EPDS (mean scores) } \\
\text { multiple RBCs; 33) }\end{array}$ & $4(1-11)$ vs $5.5(2-8) p=.34$ \\
\hline Holm et al. 2019 [24] & RCT open-label; Denmark & Moderate & $\begin{array}{l}N=85 \text { (Oral iron; 44, and EPDS (mean scores) } \\
\text { Iron isomaltoside; 41) }\end{array}$ & $\begin{array}{l}\text { MD: }-2.39 \text { (95\% Cl: }-3.62 \\
-1.16)(p=.0002)\end{array}$ \\
\hline Paoletti et al. 2013 [25] & RCT open-label; Italy & Moderate & $\begin{array}{l}N=852 \text { (Group A: 424, EPDS (cut off: } \geq 12 \text { ) } \\
\text { Group B: 428) }\end{array}$ & $P<0.05$ \\
\hline Maeda et al. 2019 [26] & Prospective cohort; Japan & Moderate & $N=1128$ EPDS ( cut off; $\geq 9$ ) & AOR: 1.63 (95\% Cl: $1.17 ; 2.26)$ \\
\hline $\begin{array}{l}\text { Chandrasekaran et al. } \\
2018[9]\end{array}$ & $\begin{array}{l}\text { Prospective Observational; } \\
\text { Canada }\end{array}$ & Moderate & $N=145 / 248$ EPDS (cut off; $\geq 10)$ & OR: 0.69 (95\% Cl: 0.15; 2.49) \\
\hline Eckerdal et al. 2016 [27] & Nested Cohort; Sweden & Moderate & $N=446$ EPDS (cut off; $\geq 12)$ & OR: 2.29 (95\% Cl:1.15; 4.58) \\
\hline Alharbi et al. 2014 [28] & Case-Control; Saudi Arabia & Moderate & $\begin{array}{l}N=352 \text { (Case: 117, Control: EPDS ( cut off; } \geq 10) \\
235)\end{array}$ & $\begin{array}{l}\text { AOR: } 1.70(95 \% \mathrm{Cl}: 1.05 ; 2.74) \\
P=0.03\end{array}$ \\
\hline Goshtasebi et al. 2013 [29] & $\begin{array}{l}\text { Prospective Observational; } \\
\text { Iran }\end{array}$ & Moderate & $N=281$ EPDS (cut off $\geq 13$ ) & $\begin{array}{l}\text { AOR: } 4.64 \text { (95\% Cl: } 1.33 \text {; } \\
\text { 16.08) }\end{array}$ \\
\hline $\begin{array}{l}\text { Armony-Sivan et al. } 2012 \\
\text { [30] }\end{array}$ & $\begin{array}{l}\text { Prospective Observational; } \\
\text { China }\end{array}$ & Moderate & $\begin{array}{l}N=248 \text { (confirmatory EPDS ( cut off; } \geq 10) \\
\text { study) }\end{array}$ & $r=0.07$ \\
\hline Albacar et al. 2010 [31] & Prospective Cohort; Spain & Moderate & $N=729$ EPDS ( cut off; $\geq 9$ ) & $\begin{array}{l}\text { OR: } 3.73(95 \% \mathrm{Cl}: 1.84 ; 7.56) \\
P=0.0001\end{array}$ \\
\hline Miller et al. 2016 [32] & $\begin{array}{l}\text { Prospective Observational; } \\
\text { USA }\end{array}$ & High & $N=63$ EPDS (cut off; $\geq 10)$ & $P>0.05$ \\
\hline Corwin et al. 2003 [33] & $\begin{array}{l}\text { Prospective Observational; } \\
\text { USA }\end{array}$ & High & $N=37$ CES-D & $r=-0.381, P=0.020$ \\
\hline Paterson et al. 1994 [34] & $\begin{array}{l}\text { Prospective observational; } \\
\text { United Kingdom }\end{array}$ & High & $N=1010$ EPDS scores & $P>0.05$ \\
\hline
\end{tabular}

Abbreviations: AOR Adjusted Odds ratio, CES-D Epidemiological Studies-Depressive Symptomatology Scale, EPDS Edinburg Postpartum Depression Scale, IDA-PL Iron deficiency anaemia-placebo, $r$ Pearson correlation coefficient

to oral iron. Conversely, Chandrasekaran et al. (2018) [9] reported no significant association between anaemia and maternal functional status (OR: 1.03, 95\% CI: 0.34, 2.94) (Table 2).

\section{Postpartum anaemia and mother-child interaction}

Four studies reported the effect of postpartum anaemia on mother-child interaction (Table 3). Murray-Kolb et al. (2009) [40] reported that at nine months' post-intervention, women who were not anaemic and the IDA-ferrous groups significantly improved scored significantly better on maternal sensitivity, non-hostility, and structuring scales and child responsiveness scale than did the IDA-placebo group ( $\mathrm{p}$-value $=0.007$ ), whose iron stores remained low. Similarly, Perez et al. (2005) [41] reported that anaemic mothers in the IDA-placebo group had negative statements towards their infants, less goal setting and responsiveness than mothers in non-anaemic and IDA-ferrous groups $(p<0.05)$ at nine months postpartum.

Unlike the above findings, Hamm et al. (2020) [23] reported that significant improvement in $\mathrm{Hb}$ levels in women who received multiple units of RBCs $(8.7 \mathrm{~g} / \mathrm{dl}$ versus $7.8 \mathrm{~g} / \mathrm{dl}$ ) did not significantly improve maternal attachment scores. Dearman et al. (2012) [42], in their pilot case-control study enrolled 115 women $(\mathrm{Hb}<10.5 \mathrm{~g} /$ $\mathrm{dl}=57$ and non-anaemic $=58)$ and reported no statistical difference in maternal perception of mother-infant bonding between the anaemic and non-anaemic group.

\section{Quality of evidence}

We used the GRADE approach to judge the strength of the evidence. Table 4 has provided the GRADE summaries with an overall quality evaluated as "moderate". The risk of bias was judged to be moderate, and inconsistency was assessed using the heterogeneity statistics. 
Table 2 Study characteristics and the association between anaemia or iron deficiency during postnatal period and maternal fatigue

\begin{tabular}{|c|c|c|c|c|c|}
\hline Author \& Year & Study Design and Setting & Risk of Bias & Sample Size & Assessment Tool & Significance \\
\hline Hamm et al. 2020 [23] & RCT open-label; USA & Moderate & $\begin{array}{l}N=66 \text { (single RBCs: } 33 \\
\text { multiple RBCs; } 33 \text { ) }\end{array}$ & MFI & $P=0.13$ \\
\hline Holm et al. 2019 [24] & RCT open-label; Denmark & Moderate & $\begin{array}{l}N=85 \text { (Oral iron; } 44, \text { and } \\
\text { Iron isomaltoside; } 41)\end{array}$ & MFI & $P<.0001$ \\
\hline Prick et al. 2014 [35] & $\begin{array}{l}\text { RCT open-label; Nether- } \\
\text { lands }\end{array}$ & Moderate & $\begin{array}{l}N=521 \text { (Non-intervention; } \\
262, \mathrm{RBC} \text {; } 259)\end{array}$ & MFI and SF-36 & $P=0.01$ \\
\hline Westad et al. 2008 [36] & RCT open-label; Norway & Moderate & $\begin{array}{l}N=128 \text { (IV + oral iron; } 58, \\
\text { oral iron only; } 70\end{array}$ & MFI and SF-36 & $P=0.03$ \\
\hline Hatzis et al. 2003 [37] & $\begin{array}{l}\text { Matched intervention trial; } \\
\text { Greece }\end{array}$ & Moderate & $\begin{array}{l}N=74(E P O ; 37 \text { and oral } \\
\text { iron; } 37)\end{array}$ & $\begin{array}{l}\text { Physical assess- } \\
\text { ment: clinical } \\
\text { symptoms of } \\
\text { fatigue }\end{array}$ & $P=0.0012$ \\
\hline $\begin{array}{l}\text { Chandrasekaran et al. } 2018 \\
\text { [9] }\end{array}$ & $\begin{array}{l}\text { Prospective Observational; } \\
\text { Canada }\end{array}$ & Moderate & $N=248$ & SF-36 & OR: 1.03 (95\% Cl: 0.34; 2.94) \\
\hline $\begin{array}{l}\text { Van Der Woude et al. } 2014 \\
\text { [8] }\end{array}$ & $\begin{array}{l}\text { Prospective Cohort; Neth- } \\
\text { erlands }\end{array}$ & Moderate & $\begin{array}{l}N=220 \text { (Anaemic; } 112, \text { No } \\
\text { anaemia; 108) }\end{array}$ & SF-36 & $P=0.008^{\mathrm{a}}$ \\
\hline Miller et al. 2016 [32] & $\begin{array}{l}\text { Prospective Observational; } \\
\text { USA }\end{array}$ & High & $N=63$ & SF-36 and MFI & $P>0.05$ \\
\hline Jansen et al. 2007 [38] & $\begin{array}{l}\text { Prospective Cohort: Neth- } \\
\text { erlands }\end{array}$ & High & $N=141$ & $\mathrm{MFI}$ & $P=0.002$ \\
\hline Lee et al. 1999 [39] & $\begin{array}{l}\text { Prospective Observational; } \\
\text { USA }\end{array}$ & High & $N=30$ & Lee Fatigue Scale & $\begin{array}{l}r=-.27, p<.05^{b} \\
r=-.44, p=.01^{c}\end{array}$ \\
\hline Paterson et al. 1994 [34] & $\begin{array}{l}\text { Prospective Observational; } \\
\text { United Kingdom }\end{array}$ & High & $N=1010$ & $\begin{array}{l}\text { Physical assess- } \\
\text { ment: feeling low } \\
\text { energy }\end{array}$ & $P=0.05$ \\
\hline
\end{tabular}

Abbreviations: IV intravenous MFI multi-fatigue dimension inventory, SF-36 Short Form-36, $R C T$ randomised controlled trial, $R B C s$ Red Blood Cells, $r$ Pearson correlation coefficient

a Un-adjusted

${ }^{\mathrm{b}}$ Low ferritin levels

' Low haemoglobin levels

Table 3 Study characteristics and association between anaemia or iron deficiency during postnatal period and mother-child interaction or bonding

\begin{tabular}{|c|c|c|c|c|}
\hline Author \& Year & $\begin{array}{l}\text { Study Design and } \\
\text { Setting }\end{array}$ & Risk of Bias & Assessment Tool & $\begin{array}{l}\text { Effect Measure and } \\
\text { Significance }\end{array}$ \\
\hline $\begin{array}{l}\text { Murray-Kolb et al. } 2009 \\
\text { [40] }\end{array}$ & $\begin{array}{l}\text { RCT double-blind, pla- } \\
\text { cebo; South Africa }\end{array}$ & Low & $\begin{array}{l}N=95 \text { (IDA-PL; 30, IDA-Fe; Video recorder } \\
\text { 34, and control; 31) }\end{array}$ & $P=0.007-0.032^{a}$ \\
\hline Perez et al. 2005 [41] & $\begin{array}{l}\text { RCT double-blind; South } \\
\text { Africa }\end{array}$ & Low & $\begin{array}{c}N=81 \text { (IDA-PL; } 21, \text { IDA-Fe; Parent/Caregiver Involve- } \\
30 \text { and Control; 30) } \quad \text { ment Scale }\end{array}$ & $P<0.05$ \\
\hline Hamm et al. 2020 [23] & RCT open-label; USA & Moderate & $\begin{array}{l}N=66 \text { (single RBCs; 33, Maternal Attachment } \\
\text { multiple RBCs; 33) } \quad \text { Inventory }\end{array}$ & $\begin{array}{l}104(102-104) \text { vs } 104 \\
(102-104) p=0.55^{b}\end{array}$ \\
\hline Dearman et al. 2012 [42] & Case-Control; England & Moderate & $\begin{array}{l}N=115 \text { (anaemic; 57, non- Postpartum Bonding } \\
\text { anaemic; 58) Questionnaire }\end{array}$ & $P>0.05$ \\
\hline
\end{tabular}

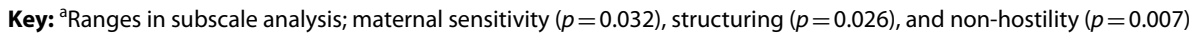

${ }^{\mathrm{b}}$ median score (range)

\section{Discussion of results}

The purpose of the present study was to determine the effect of postpartum anaemia on the three domains of HRQoL in a postpartum woman. Studies have reported mixed findings on the association between iron deficiency and postpartum depression. This is despite the physiological link that iron is required to produce the behavioural neurotransmitter dopamine, and lack of it is clinically manifested by symptoms such as depression and fatigue [45]. Our pooled results from comparisons of dichotomous data from observational studies indicated that iron deficiency or anaemia measured at different time points during the first postpartum year is a significant risk factor for postpartum depression. Our findings 


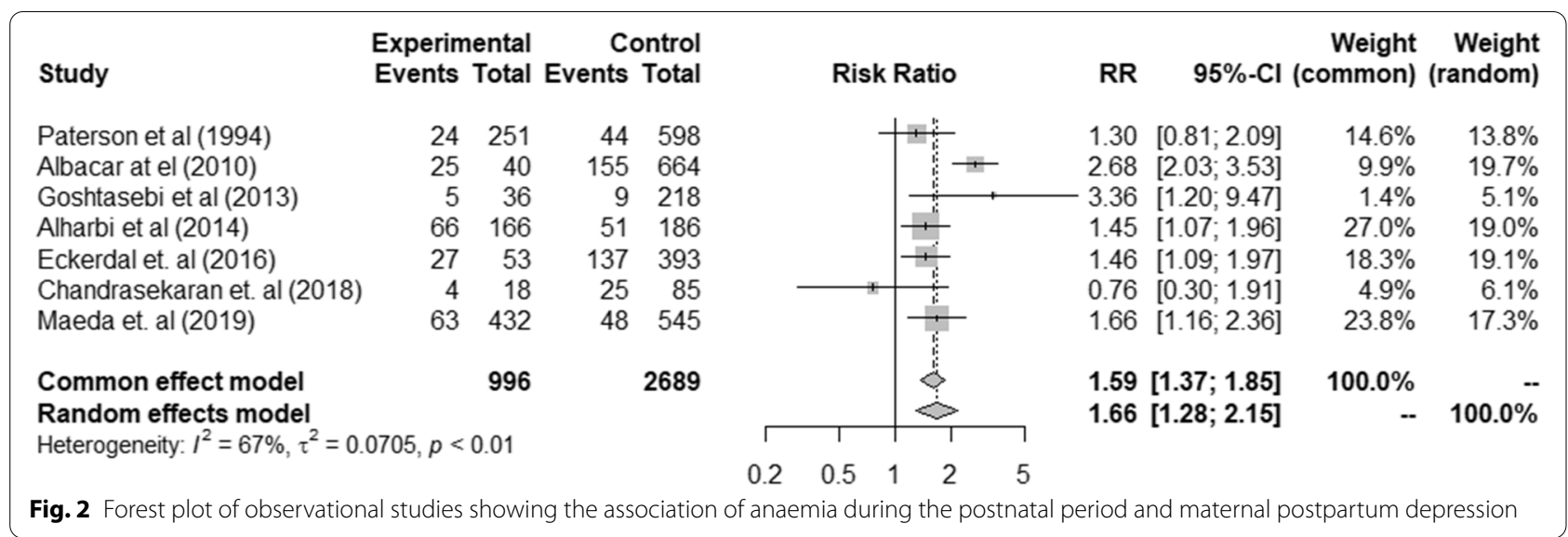

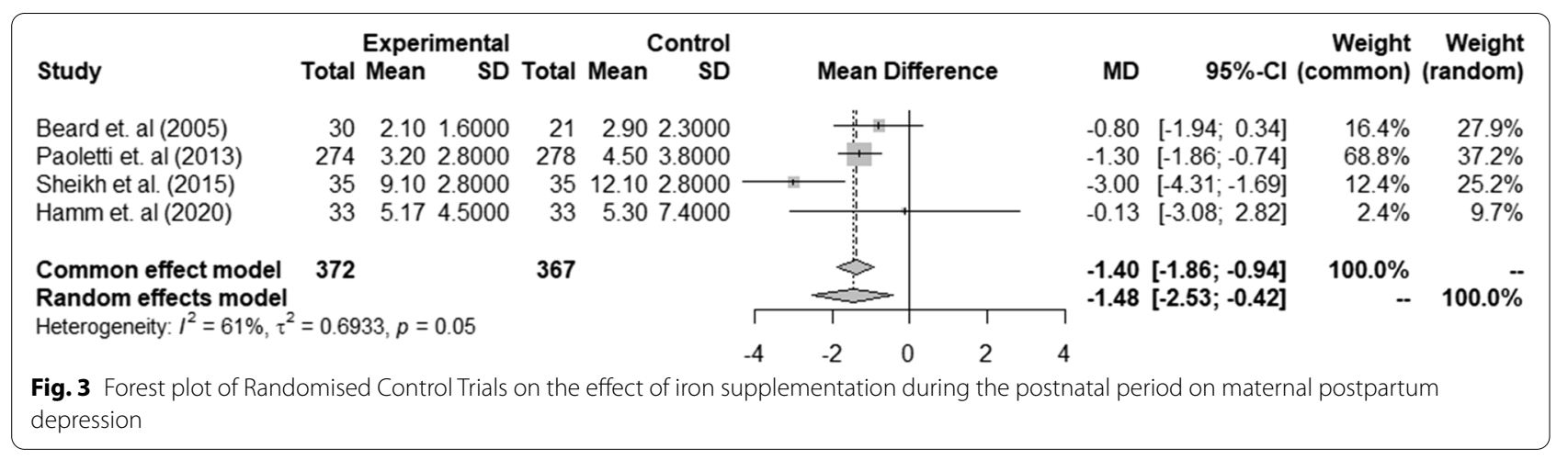

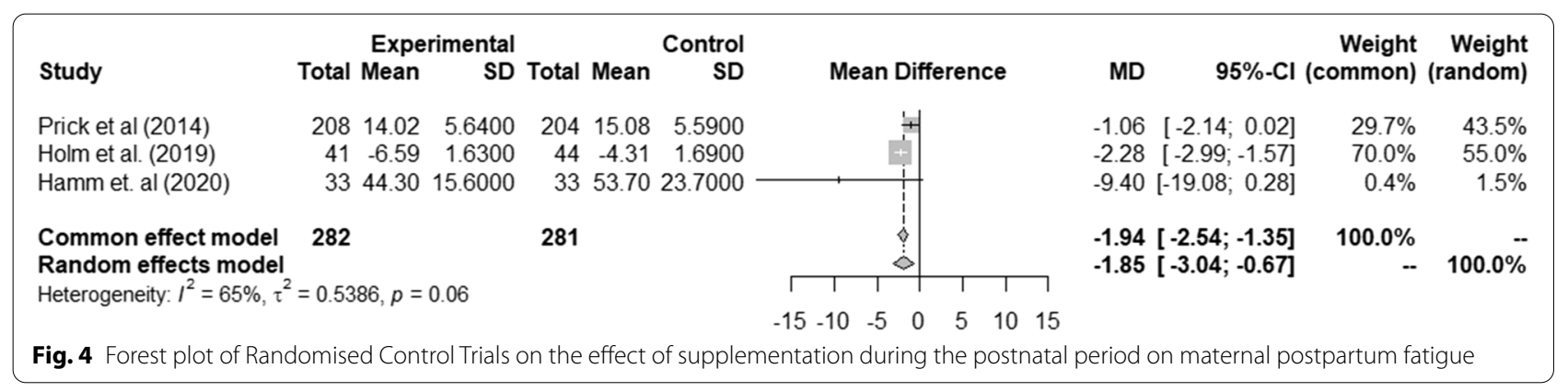

Table 4 GRADE assessment of confidence in effect size

\begin{tabular}{|c|c|c|c|c|c|c|}
\hline Outcome & Risk of Bias & Consistency & Indirectness & Imprecision & Publication Bias & $\begin{array}{l}\text { Strength of } \\
\text { Evidence }\end{array}$ \\
\hline $\begin{array}{l}\text { Postpartum anaemia } \\
\text { or ID on PPD (Obser- } \\
\text { vational Studies) }\end{array}$ & No serious limitation & No serious limitation & No serious limitation & No serious limitation & No serious limitation & Moderate \\
\hline $\begin{array}{l}\text { Postpartum anaemia } \\
\text { or ID on PPD (RCTs) }\end{array}$ & No serious limitation & No serious limitation & No serious limitation & No serious limitation & No serious limitation & Moderate \\
\hline $\begin{array}{l}\text { Postpartum anaemia } \\
\text { or ID on fatigue (con- } \\
\text { tinuous data) }\end{array}$ & No serious limitation & No serious limitation & No serious limitation & No serious limitation & No serious limitation & Moderate \\
\hline
\end{tabular}


are similar to those of a recent meta-analysis which also reported significant associations between postpartum anaemia and symptoms of depression [46].

The other important findings from the pooled continuous data from RCTs showed that iron supplementation significantly increased iron and haemoglobin levels with a corresponding significant decrease in depression scores. The heterogeneity test $\left(\mathrm{I}^{2}=61 \%\right)$ was substantially high with a borderline significant value $(p=0.05)$. Variations in the type of the interventions and comparators (such as intravenous iron versus oral iron/placebo, a single unit of blood versus multiple units), use of different intervention dosages and variations in the timing of measuring depression might explain the observed substantial heterogeneity.

Two important findings on the effect of postpartum anaemia on maternal fatigue were noted. Firstly, pooled evidence suggests that anaemia as indicated by low $\mathrm{Hb}$ or depleted iron stores is associated with maternal postpartum fatigue, and can be treated by iron replenishment $\left[\mathrm{I}^{2}=65.0 \%, p=0.06\right.$, (MD: -1.85 , 95\% CI: 3.04; -0.67) $]$ in either strategy. This finding is similar to a previous systematic review investigating the impact of intravenous iron treatment on HRQoL in patients with IDA [47]. Secondly, little attention has been paid to the same condition in developing countries, and it remains unclear whether the above findings are applicable in the African context. A meta-analysis by Badr et al. (2017) [48] aimed at identifying predicting factors for maternal postpartum fatigue called authors to explore whether race/geographical region can mediate the association between iron deficiency and postpartum fatigue.

The association between anaemia and mother-child interaction/bonding remains unclear. Globally, researchers have paid little attention to this area. We only identified four studies that showed mixed findings, and their conclusions were not pooled due to the outcome being reported differently among studies. Two well-conducted studies $[40,41]$ reported that maternal anaemia negatively impacted mother-child interaction. Other studies that reported no association also had some shortfalls. For example, the sample size in Hamm et al. (2020) [23] was not powered to evaluate the effects of anaemia on secondary outcomes such as mother-child attachment. Dearman et al. (2012) [42] also acknowledged that lack of association in their study might be due to the small sample size lacking power.

\section{Study Limitation}

Our study has two major limitations. Firstly, we limited our search to human studies published in English language only because none of the authors is conversant with other languages. Secondly, we did not produce funnel plots to assess publication bias in the included studies, as less than ten studies were included in each meta-analysis.

\section{Conclusion}

To our knowledge, this is the first systematic review that has determined the effect of postpartum anaemia on maternal health-related quality of life in a holistic approach by incorporating all domains of HRQoL. While it is clear from our findings that postpartum anaemia negatively affects health-related quality of life domains of physical and mental health and that iron replenishment tremendously improved symptoms of fatigue and depression, it remains unclear on its impact on motherchild interaction. There is a paucity of data from developing countries on the effect of postpartum anaemia on HRQoL. We, therefore, call for well-designed studies in Africa to provide contextual evidence. Nonetheless, we agree and call upon clinicians in developing countries to adhere to the World Health Organisation recommendation of routine iron supplementation to women until six weeks postpartum to improve maternal HRQoL during the postpartum period.

\section{Abbreviations \\ CES-D: Center for Epidemiological Studies Depression Scale; EPDS: Edinburgh Postpartum Depression Scale; HRQoL: Health-Related Quality of Life; IDA: Iron Deficiency Anaemia; MFI: Multidimensional Fatigue Inventory scale; RBCs: Red Blood Cells; SF-36: 36-Item Short Form Survey; RCTs: Randomised Control Trials.}

\section{Supplementary Information}

The online version contains supplementary material available at https://doi. org/10.1186/s12889-022-12710-2.

Additional file 1: Search Strategies.

Acknowledgements

Not applicable

Authors' contributions

Author EM envisioned the systematic review and drafted the manuscript. NP was involved in data search and assessing articles for eligibility and the risk of bias. MNM and KP provided technical reviews and resolved disagreements between EM and NP. ATC provided statistical support. All authors read and approved the final version of the manuscript.

\section{Funding}

This systematic review was not directly funded. However, author EM is a PhD student supported by the Training and Research Unit of Excellence and Consortium for Advanced Research Training in Africa (CARTA) which is funded by the British Council, SIDA, The African Academy for Science, Ford Foundation and Wellcome Trust.

\section{Availability of data and materials}

We used data from previously published articles that have been cited in this published article. Other resources which includes data extraction forms, and detailed information pertaining risk of bias can be provided by corresponding author upon request. 


\section{Declarations}

Ethics approval and consent to participate

Not applicable.

\section{Consent for publication}

Not applicable.

\section{Competing interest}

All authors declare no competing interest.

\section{Author details}

${ }^{1}$ Training and Research Unit of Excellence (TRUE), 1 Kufa Road, Chichiri, BT3, PO Box 30538, Blantyre, Malawi. '²epartment of Public Health, School of Public Health and Family Medicine, College of Medicine, Kamuzu University of Health Sciences, Private Bag 360, Chichiri, BT3, Blantyre, Malawi. ${ }^{3}$ College of Medicine, Malawi-Liverpool Wellcome Trust Queen Elizabeth Central Hospital, PO Box 30096, Chichiri, Blantyre, Malawi.

Received: 16 April 2021 Accepted: 31 January 2022

Published online: 21 February 2022

\section{References}

1. Milman N. 2015. Postpartum Anemia - Still a Major Problem on a Global Scale. J Pregnancy Child Heal 02:4172 https://doi.org/10.4172/2376-127X. $1000 \mathrm{e} 122$

2. World Health Organisation. 2016. Guideline Iron Supplementation in postpartum women. http://www.who.int

3. Milman N. 2012. Postpartum anemia II: Prevention and treatment. Ann Hematol 91:143-154: https://doi.org/10.1007/s00277-011-1381-2

4. Mirza FG, Abdul-Kadir R, Breymann C, Fraser IS, Taher A. Impact and management of iron deficiency and iron deficiency anemia in women's health. Expert Rev Hematol. 2018;11:727-36. https://doi.org/10.1080/ 17474086.2018.1502081.

5. World Health Organisation. 2004 Assessing the Iron Status of Population. ISBN 9789241596107

6. Ando K, Morita S, Higashi T, Fukuhara S, Watanabe S, Park J, Kikuchi M, Kawano K, Wasada I, Hotta T. Health-related quality of life among Japanese women with iron-deficiency anemia. Qual Life Res. 2006;15:1559-63 Accessed: 11-06-2020 19:15 UTC https://www.jstor.org/stable/27641234.

7. Yilmaz E. The Impact of Iron Deficiency Anemia on Health Related Quality of Life in the Last Trimester of Pregnancy. Eurasian J Med Investig. 2019;3:182-8. https://doi.org/10.14744/ejmi.2019.65035.

8. Van Der Woude D, Pijnenborg JMA, Verzijl JM, Van Wijk EM, De Vries J. Health status and fatigue of postpartum anemic women: A prospective cohort study. Eur J Obstet Gynecol Reprod Biol. 2014;181:119-23. https:// doi.org/10.1016/j.ejogrb.2014.07.028.

9. Chandrasekaran N, De Souza LR, Urquia ML, Young B, Mcleod A, Windrim $\mathrm{R}$, Berger $\mathrm{H}$. Is anemia an independent risk factor for postpartum depression in women who have a cesarean section? - A prospective observational study. BMC Pregnancy Childbirth. 2018;18:1-7. https://doi.org/10. 1186/s12884-018-2032-6.

10. Khalafallah AA, Dennis AE. Iron deficiency anaemia in pregnancy and postpartum: Pathophysiology and effect of oral versus intravenous iron therapy. J Pregnancy. 2012. https://doi.org/10.1155/2012/630519.

11. Rezaei N, Tavalaee Z, Sayehmiri K, Sharifi N, Daliri S. The relationship between quality of life and methods of delivery A systematic review and meta-analysis. Electron Physician. 2018;10:6596-607 (http://dx.doi.org/10. 19082/6596)

12. Ojelabi AO, Graham Y, Haighton C, Ling J. A systematic review of the application of Wilson and Cleary health-related quality of life model in chronic diseases. 2017. https://doi.org/10.1186/s12955-017-0818-2.

13. Moher D, Liberati A, Tetzlaff J, Altman DG. Preferred reporting items for systematic reviews and meta-analyses: The PRISMA statement. BMJ. 2009;339:332-6. https://doi.org/10.1371/journal.pmed.1000097.

14. Yim IS, Tanner Stapleton LR, Guardino CM, Hahn-Holbrook J, Dunkel Schetter C. Biological and psychosocial predictors of postpartum depression: Systematic review and call for integration. Annu Rev Clin Psychol. 2015;11:99-137. https://doi.org/10.1146/annurev-clinp sy-101414-020426.

15. Wells GA, D O'Connell, J Peterson, VWelch, M Losos, P Tugwell BS (2014) Newcastle-Ottawa quality assessment scale. BMJ. 2016;355:i4919. Ottawa Hosp Res Institute, 2-4. http://dx.doi.org/10.1136/bmj.i4919.

16. Sharmin S, Kypri K, Khanam M, Wadolowski M, Bruno R, Mattick RP (2017) Parental supply of alcohol in childhood and risky drinking in adolescence: Systematic review and meta-analysis. Int J Environ Res Public Health. https://doi.org/10.3390/ijerph14030287

17. Sterne JA, Hernán MA, Reeves BC, et al. ROBINS-I: A tool for assessing risk of bias in non-randomised studies of interventions. BMJ. 2016:355:4-10. https://doi.org/10.1136/bmj.i4919/.

18. Guyatt G, Oxman AD, Akl EA, Kunz R, Vist G, Brozek J, Norris S, Falck-ytter Y, Glasziou P, Jaeschke R (2011) GRADE guidelines : 1 . Introduction d GRADE evidence profiles and summary of findings tables. https://doi.org/ 10.1016/j.jclinepi.2010.04.026

19. Wan X, Wang W, Liu J, Tong T. Estimating the sample mean and standard deviation from the sample size, median, range and/or interquartile range. BMC Med Res Methodol. 2014;14:135. http://www.biomedcentral.com/ 1471-2288/14/135.

20. Sheikh M, Hantoushzadeh S, Shariat M, Farahani Z, Ebrahiminasab O. The efficacy of early iron supplementation on postpartum depression, a randomized double-blind placebo-controlled trial. Eur J Nutr. 2017:56:901-8

21. Perellõ MF, Coloma JL, Masoller N, Esteve J, Palacio M. Intravenous ferrous sucrose versus placebo in addition to oral iron therapy for the treatment of severe postpartum anaemia: A randomised controlled trial. BJOG An Int J Obstet Gynaecol. 2014;121:706-13. https://doi.org/10.1111/14710528.12480.

22. Beard JL, Hendricks MK, Perez EM, Murray-kolb LE, Berg A, Vernon-feagans L, Irlam J, Isaacs W, Sive A, Tomlinson M. Maternal Iron Deficiency Anemia Affects Postpartum Emotions and Cognition. J Nutr. 2005;135(2):267-72.

23. Hamm RF, Perelman S, Wang EY, Levine LD, Srinivas SK. Single-unit vs multiple-unit transfusion in hemodynamically stable postpartum anemia: a pragmatic randomized controlled trial. Am J Obstet Gynecol. 2021;224:84.e1-84.e7. https://doi.org/10.1016/j.ajog.2020.07.007.

24. Holm C, Thomsen LL, Langhoff-Roos J. Intravenous iron isomaltoside treatment of women suffering from severe fatigue after postpartum hemorrhage. J Matern Neonatal Med. 2019;32:2797-804 10.1080/14767058.2018.1449205.

25. Paoletti AM, Orrù MM, Marotto MF, et al. Observational study on the efficacy of the supplementation with a preparation with several minerals and vitamins in improving mood and behaviour of healthy puerperal women. Gynecol Endocrinol. 2013;29:779-83. https://doi.org/10.3109/ 09513590.2013.801447

26. Maeda Y, Ogawa K, Morisaki N, Tachibana Y, Horikawa R, Sago H. Association between perinatal anemia and postpartum depression: A prospective cohort study of Japanese women. Int J Gynecol Obstet. 2020;148:4852. https://doi.org/10.1002/ijgo.12982.

27. Eckerdal P, Kollia N, Löfblad J, Hellgren C, Karlsson L, Högberg U, Wikström AK, Skalkidou A. Delineating the association between heavy postpartum haemorrhage and postpartum depression. PLOS ONE. 2016;11:1-14.

28. Alharbi AA, Abdulghani HM. Risk factors associated with postpartum depression in the Saudi population. Neuropsychiatr Dis Treat. 2014;10:311-6

29. Goshtasebi A, Alizadeh M, Gandevani SB. Association between maternal anaemia and postpartum depression in an urban sample of pregnant women in Iran. J Heal Popul Nutr. 2013;31:398-402.

30. Armony-Sivan $\mathrm{R}$, Shao J, Li M, et al. No relationship between maternal iron status and postpartum depression in two samples in China. J Pregnancy. 2012;2012:13-5. https://doi.org/10.1155/2012/521431.

31. Albacar G, Sans T, Martín-Santos R, et al. An association between plasma ferritin concentrations measured $48 \mathrm{~h}$ after delivery and postpartum depression. J Affect Disord. 2011;131:136-42.

32. Miller CM, Ramachandran B, Akbar K, Carvalho B, Butwick AJ. The impact of postpartum hemoglobin levels on maternal quality of life after delivery: a prospective exploratory study. Ann Hematol. 2016;95:2049-55. https://doi.org/10.1007/s00277-016-2817-5. 
33. Corwin EJ, Murray-Kolb LE, Beard JL. Low Hemoglobin Level Is a Risk Factor for Postpartum Depression. J Nutr. 2003;133:4139-42. https://doi.org/ 10.1093/jn/133.12.4139.

34. Paterson JA, Davis J, Gregory M, J.R. Holt S, Pachulski A, Stamford DEC, Wothers JB, Jarrett A. A study on the effects of low haemoglobin on postnatal women. Midwifery. 1994;10:77-86. https://doi.org/10.1016/ S0266-6138(05)80249-9.

35. Prick BW, Jansen AJG, Steegers EAP, et al. Transfusion policy after severe postpartum haemorrhage: A randomised non-inferiority trial. BJOG An Int J Obstet Gynaecol. 2014;121:1005-14. https://doi.org/10.1111/1471-0528. 12531.

36. Westad S, Backe B, Salvesen KÅ, Nakling J, Økland I, Borthen I, Rognerud Jensen $\mathrm{OH}$, Kolås T, Løkvik B, Smedvig E. A 12-week randomised study comparing intravenous iron sucrose versus oral ferrous sulphate for treatment of postpartum anemia. Acta Obstet Gynecol Scand. 2008;87:91623. https://doi.org/10.1080/00016340802317802.

37. Hatzis T, Cardamakis E, Tsapanos V, Kourounis G, Linardos N, Mantouvalos $H$, Tzingounis $V$. The effects of recombinant human erythropoietin given immediately after delivery to women with anaemia. Curr Med Res Opin. 2003;19:346-9. https://doi.org/10.1185/030079903125001802.

38. Jansen AJG, Duvekot JJ, Hop WCJ, Essink-Bot ML, Beckers EAM, Karsdorp VHM, Scherjon SA, Steegers EAP, Van Rhenen DJ. New insights into fatigue and health-related quality of life after delivery. Acta Obstet Gynecol Scand. 2007;86:579-84. https://doi.org/10.1080/0001634070 1275424.

39. Lee KA, Zaffke ME. Longitudinal changes in fatigue and energy during pregnancy and the postpartum period. J Obstet Gynecol Neonatal Nurs. 1999;28:183-91. https://doi.org/10.1111/j.1552-6909.1999.tb01983.x.

40. Murray-Kolb LE, Beard JL. Iron deficiency and child and maternal health. Am J Clin Nutr. 2009;89:946-50 https://academic.oup.com/ajcn/ article-abstract/89/3/946S/4596801.

41. Perez EM, Hendricks MK, Beard JL, et al. Mother-infant interactions and infant development are altered by maternal iron deficiency anemia. J Nutr. 2005;135:850-5. https://doi.org/10.1093/jn/135.4.850.

42. Dearman LR, Musonda P, Roberts FG, Bowles KM, Morris EP. Bonding in women with postnatal anaemia: A pilot case control study looking at postnatal bonding in women who have been diagnosed with anaemia at a University Hospital in the East of England. Arch Gynecol Obstet. 2012;285:1243-8. https://doi.org/10.1007/s00404-011-2142-0.

43. Meyer JW, Eichhorn KH, Vetter K, Christen S, Schleusner E, Klos A, Huch A, Huch R. Does recombinant human erythropoietin not only treat anemia but reduce postpartum (emotional) distress as well? J Perinat Med. 1995;23:99-110. https://doi.org/10.1515/jpme.1995.23.1-2.99.

44. Güven Z, Holm C, Rosthoej S, Langhoff-Roos J. Association between blood loss at delivery and fatigue in the puerperium: a prospective longitudinal study. J Matern Neonatal Med. 2020;33:606-11 10.1080/14767058.2018.1498479.

45. Wessling-Resnick JK and M (2015) Iron and Mechanisms of Emotional Behavior Jonghan. 25:1101-1107 https://doi.org/10.1016/j.jnutbio.2014 07.003

46. Azami M, Badfar G, Khalighi Z, Qasemi P, Shohani M, Soleymani A, Abbasalizadeh S. The association between anemia and postpartum depression: A systematic review and meta-analysis. Casp J Intern Med. 2019;10:115-24. https://doi.org/10.1016/j.jpsychires.2020.01.001.

47. Strauss $W$, Auerbach $M$. Health-related quality of life in patients with iron deficiency anemia: impact of treatment with intravenous iron. Patient Relat Outcome Meas. 2018;9:285-98. https://doi.org/10.2147/prom.s1696 53.

48. Badr HA, Zauszniewski JA. Meta-analysis of the predictive factors of postpartum fatigue. Appl Nurs Res. 2017;36:122-7. https://doi.org/10.1016/j. apnr.2017.06.010.

\section{Publisher's Note}

Springer Nature remains neutral with regard to jurisdictional claims in published maps and institutional affiliations.

Ready to submit your research? Choose BMC and benefit from:

- fast, convenient online submission

- thorough peer review by experienced researchers in your field

- rapid publication on acceptance

- support for research data, including large and complex data types

- gold Open Access which fosters wider collaboration and increased citations

- maximum visibility for your research: over $100 \mathrm{M}$ website views per year

At BMC, research is always in progress.

Learn more biomedcentral.com/submissions 